\title{
The Changing Landscape - Palliative Care in the Heart Failure Patient Population
}

\author{
Michael Slawnych ${ }^{1}$, Jessica Simon ${ }^{1}$ and Jonathan Howlett ${ }^{2}$ \\ ${ }^{1}$ Division of Palliative Medicine, \\ ${ }^{2}$ Department of Cardiac Sciences, University of Calgary, \\ Canada
}

\section{Introduction}

The practice of cardiovascular medicine has changed dramatically over the course of the last several decades (Figure 1). Heart failure (HF), a condition characterized by damaged myocardium, abnormal ventricular filling and/or ejection, and symptoms of vascular congestion or poor cardiac output, was once deemed a terminal illness with few good therapeutic options. However, advances in treatment have led to significant increases in life expectancy and quality of life. Patients with HF now have numerous medication options available. In select patient subsets, these medications are associated with greater than $80 \%$ reductions in mortality. Current clinical guidelines support the implantation of implantable cardioverter defibrillators (ICDs) for both primary and secondary prevention indications. Cardiac resynchronization therapy (CRT) extends the efficacy of these devices in specific patient subgroups. External mechanical support devices, previously considered as a temporizing measure, are now being used as at as permanent therapy. Trans-catheter aortic valve implantation (TAVI) has not only been shown to be vastly superior to medical therapy in non-operative patients with severe aortic stenosis, but is also being considered as an alternative to cardiac surgery in lower risk groups.

As a result of all of these advances, there has been a shift in the cardiac patient demographic. Current patients with HF are older, have more co-morbidities, and take more medications than in the past (Wong et al. 2011). This trend is likely to continue, as the proportion of elderly individuals is projected to increase for some time (Foot et al. 2000).

As early as the 1960's it was recognized that HF was associated with significant levels of mental and physical distress, with this distress sometimes exceeding that observed in other populations such as cancer (Hinton 1963). The progress of medical and technological developments that prolong life may initially appear to have made palliative care appear irrelevant for the cardiac patient population. Ironically though, nearly all of our treatment advances for such patients are not in fact, cures. Thus patients will eventually become refractory to even these treatment modalities, which will necessitate complex symptom management. In this setting, care deliver by a multidisciplinary team that includes palliative care is needed. Patients with HF continue to suffer mortality rates greater than $40 \%$ over 5 years (Lloyd-Jones et al. 2010). Lessons can be taken from the cancer literature that shows 
that the early introduction of palliative care as an adjunct to disease-focused treatment not only improves quality of life, but can increase longevity as well (Temel et al. 2010).

While palliative care is now incorporated into several HF guidelines, implementation is still lacking. This is likely a reflection of several barriers (Selman, Harding, and Beynon 2007) not the least of which is the physician and patient comfort in focusing on life-prolonging therapies and a reluctance to acknowledge or plan for death as an outcome of advancing disease. This tension is amplified by the inherent difficulty in estimating prognosis in this patient population, given the highly variable course of advanced HF. While there are now several models that provide prognostic guidance, they are most useful for estimating outcomes in patient populations as opposed to individual patients (McKelvie et al. 2011). In this chapter, we highlight opportunities for incorporating palliative care to the HF population, despite the uncertain prognosis.

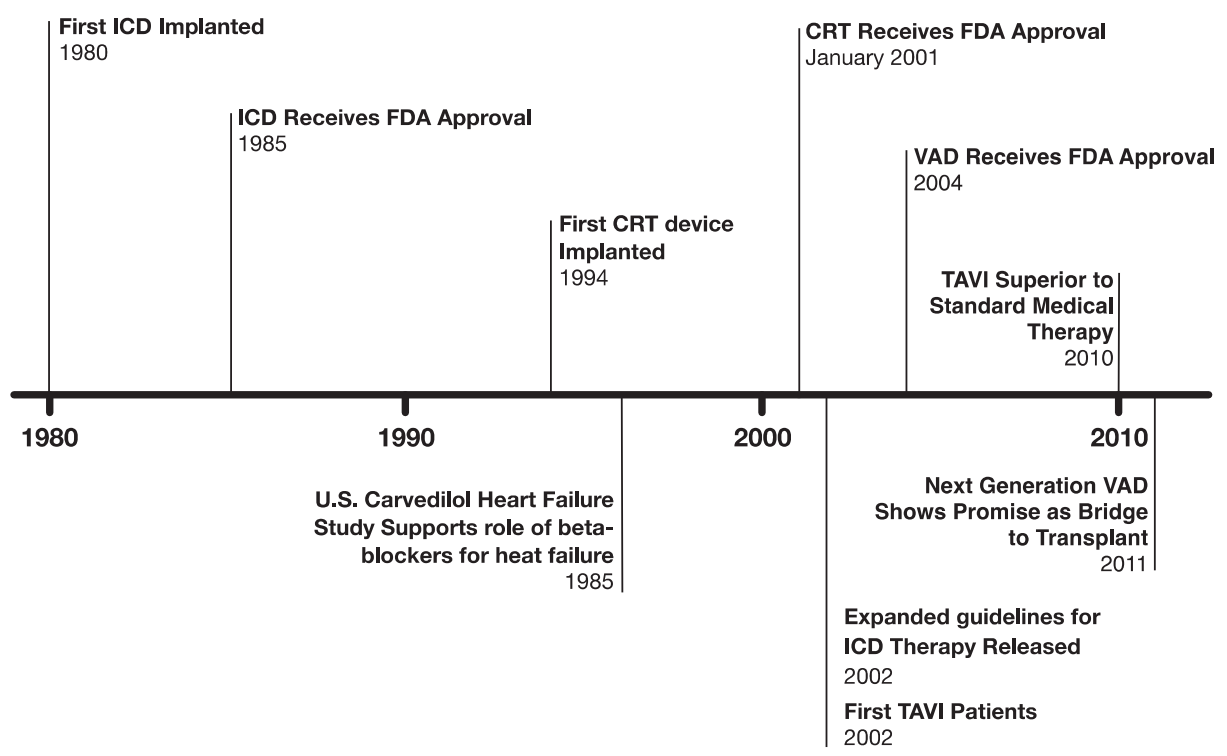

Fig. 1. Treatment advances in cardiology (1980 - present).

\section{Heart failure - Some basic facts}

Heart failure is common. There are close to six million Americans living with HF, with 670,000 new cases diagnosed annually (Lloyd-Jones et al. 2010). The prevalence of HF increases significantly with age, and is noted to be greater than $20 \%$ in patients greater than 80 years of age (Lloyd-Jones et al. 2010). As a result, HF has become a significant health care burden, particularly in developed countries (Braunschweig, Cowie, and Auricchio 2011). With the expected doubling of the number of Americans older than 65 years during the next few decades, an marked increase in the number of patients with HF (Abouezzeddine and Redfield 2011) will occur.

There are many causes of heart failure, including ischemia, hypertension, valvular heart disease, arrhythmias and primary cardiomyopathies. The typical symptoms associated with 
HF include dyspnea, fatigue, and reduced exercise tolerance, but many other symptoms including pain and psycho-social suffering are associated with advanced disease (Scott A Murray et al. 2002; Nordgren and Sörensen 2003).

$\mathrm{HF}$ is the leading cause of hospital admissions in patients greater than 65 years of age. Hospitalization is an independent risk factor for shortened survival in patients with chronic $\mathrm{HF}$, and is associated with an average life expectancy of approximately two years (Howlett 2011), which is less than that of many cancers. Even as the national death rate decreased by 2\% from 1994 to 2004, deaths due to heart failure increased by 28\% (Adler et al. 2009).

The severity of heart failure is commonly assessed using the well-known New York Heart Association (NYHA) classification scheme, which categorizes patients on the basis of limitation of physical activity (Table 1). In 2001, the American College of Cardiology (ACC) and the American Heart Association (AHA) developed a complementary classification scheme for HF, which progressively categorizes patients on the basis of the presence of cardiac risk factors, cardiac structural impairment, symptoms of heart failure, and then culminating in refractory disease (Figure 2). This classification scheme emphasizes evidencebased treatment for each stage, as well as disease prevention. Specifically, the first stage can be viewed as "pre-heart failure" where risk factor intervention can potentially prevent progression to overt symptoms. Of note, this first stage does not have a corresponding NYHA class.

Class I - No limitation of physical activity

- Ordinary physical activity not associated with symptoms (fatigue, palpitation, or dyspnea).

Class II - Slight limitation of physical activity

- Comfortable at rest, but ordinary physical activity results symptoms.

Class III - Moderate limitation of physical activity

- $\quad$ Comfortable at rest, but less than ordinary activity causes symptoms.

Class IV - Severe limitation of physical activity

- Unable to carry out any physical activity without discomfort. Symptoms at rest.

Table 1. NYHA classification scheme.

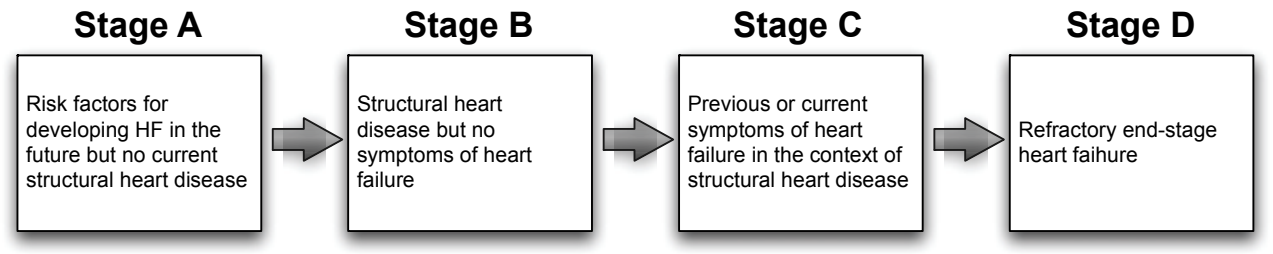

Fig. 2. ACC/AHA heart failure classification scheme.

While the disease trajectory of each individual HF patient is unique (Gott pall med 2007), there is a general overall theme (Murray et al. 2007; Murray and Skeikh 2008; Goodlin 2009). Typically, several episodes of acute "decompensation" are observed on a background of gradual decline, subsequently progressing to "end-stage" HF (Figure 3). Some patients, such as those with large anterior myocardial infarctions, will go through these transitions very quickly. For other patients, these transitions can take decades. 


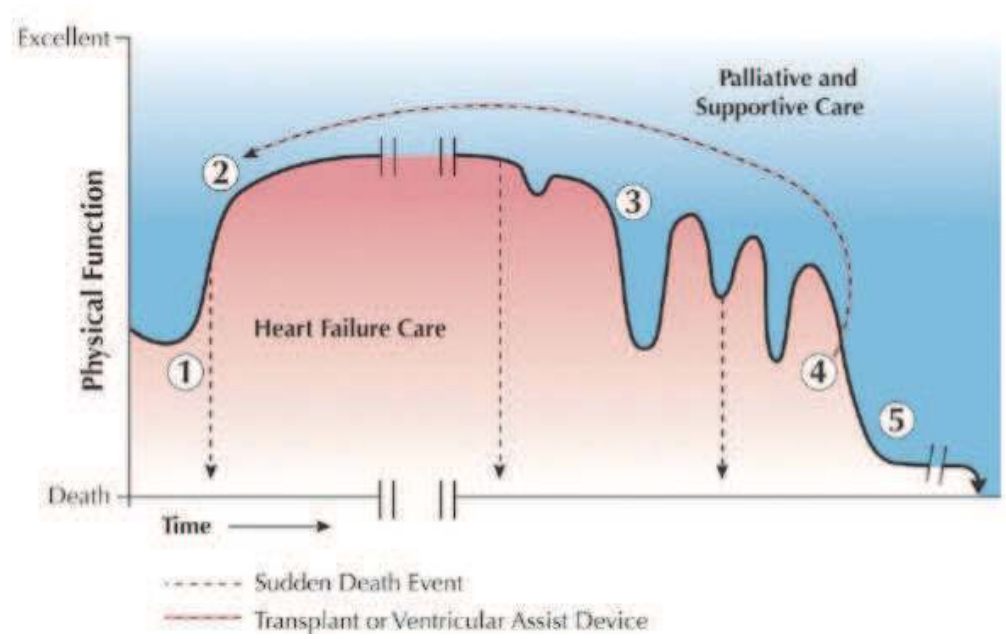

Fig. 3. Heart failure disease trajectory (from Goodlin 2009).

While there is no universally accepted definition of "end-stage" HF, it typically refers to ACC/AHA Stage D patients who have refractory symptoms despite maximal medical therapy (Murthy and Lipman 2011). Some of these "end-stage" patients may be candidates for advance treatment modalities such as transplant or self-contained mechanical support (i.e. LVAD), thus resetting the disease trajectory. However there is a limited availability of donor hearts, and most patients with HF will not benefit from advanced HF therapies such a mechanical support LVAD implantation, leaving many patients without these options.
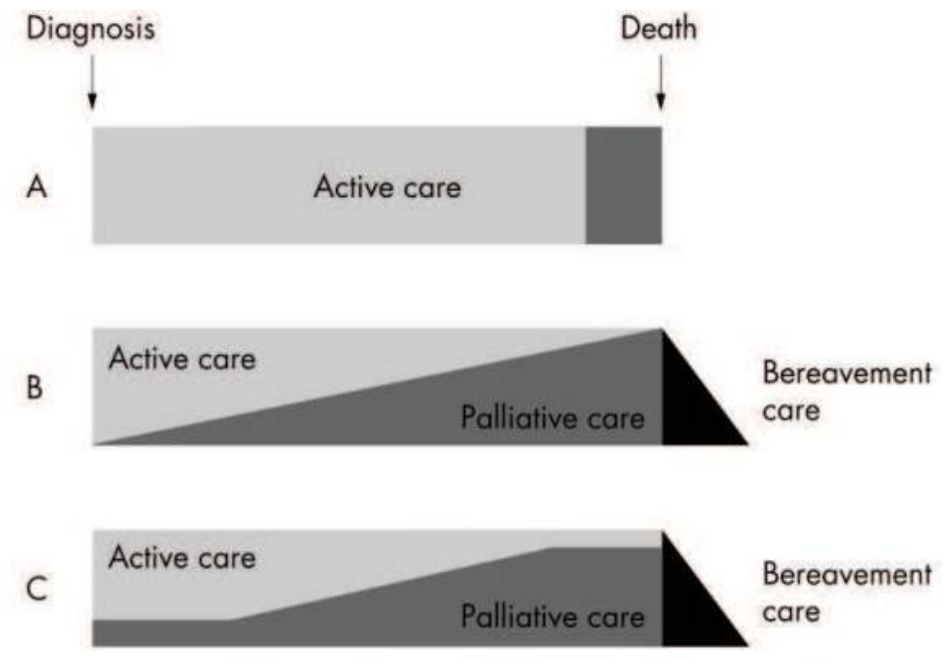

Figure 2 Models showing involvement of palliative care in cancer (A and B) and a proposed model for heart failure (C).

Fig. 4. Model of palliative care for HF (from Gibbs et al. 2002). 
As HF progresses and patients deteriorate to a poorer functional status, hospitalization rates increase. Health care resource utilization is particularly high in the last few months of life. A recent study of 30,000 Canadian patients who died with HF showed that more than $75 \%$ were hospitalized during the last 6 months of life and $>50 \%$ died while in hospital (Kaul et al. 2011). In this context, Murray and colleagues developed a HF classification scheme that recognizes the three different treatment phases that most patients with HF will go through (Table 2). What sets this scheme apart from the more commonly employed NYHA and ACC/AHA classifications is that for the first time, all stages of heart failure are related to the World Health Organization (WHO) definition of palliative care. This classification scheme forms an integral component of the European position statement on palliative care in heart failure (Jaarsma et al. 2009). It should be noted that the idea of early introduction of palliative care to the HF patient population is not unique. Gibbs and colleagues (Gibbs et al. 2002) proposed a model of HF management in which palliative care plays a prominent role throughout all stages of treatment (figure 4).

\section{Stage 1: Chronic disease management phase (NYHA I-III)}

- The goals of care include active monitoring, effective therapy to prolong survival, symptom control, patient and carer education, and supported

- $\quad$ self-management.

- Patients are given a clear explanation of their condition including its name, aetiology, treatment, and prognosis.

- Regular monitoring and appropriate review according to national guidelines and local protocols

Stage 2: Supportive and palliative care phase: (NYHA III-IV)

- Admissions to hospital may herald this phase.

- A key professional is identified in the community to co-ordinate care and liaise with specialist heart failure, palliative care, and other services.

- The goal of care shifts to maintaining optimal symptom control and quality of life.

- A holistic, multidisciplinary assessment of patient and carer needs takes place.

- Opportunities to discuss prognosis and the likely course of the illness in more detail are provided by professionals, including recommendation for completing an advance care plan.

- Out-of-hours services are documented in care plans in the event of acute deterioration

\section{Stage 3: Terminal care phase}

- Clinical indicators include, despite maximal treatment, renal impairment, hypotension, persistent oedema, fatigue, anorexia

- Heart failure treatment for symptom control is continued and resuscitation status clarified, documented, and communicated to all care providers

- An integrated care pathway for the dying may be introduced to structure care planning

- Increased practical and emotional support for carers is provided, continuing to bereavement support

- Provision of and access to the same levels of generalist and specialist care for patients in all care settings according to their needs

Table 2. Characteristics of the three stages in progressive heart failure (from Jaarsma et al., 2009) 


\section{Incorporation of palliative care to the heart failure patient population}

Historically, palliative care has been associated primarily with cancer patients. In this regard, there is now a significant body of literature that shows that the incorporation of palliative care has resulted in better symptom control for these patients. Patients and families also benefit from other factors such as improved psychological support and patient advocacy. There is also new literature showing that the early introduction of palliative care in this patient population can increase longevity as well (Temel et al. 2010).

Canadian Cardiovascular Society (McKelvie et al. 2011)

- "We recommend that the provision of palliative care to patients with HF should be based on a thorough assessment of needs and symptoms, rather than on individual estimate of remaining life expectancy "

- "We recommend that the presence of persistent advanced HF symptoms (NYHA IIIIV) despite optimal therapy be confirmed, ideally by an interdisciplinary team with expertise in HF management, to ensure appropriate HF management strategies have been considered and optimized, in the context of patient goals and comorbidities"

- "We recommend an interdisciplinary chronic care model for the organization and delivery of palliative care to patients with advanced HF"

ACC/AHA (Jessup et al. 2009)

- " ... palliative care for patients with chronic HF should be addressed as an ongoing key component of their plan of care, especially when hospitalized with acute decompensation"

European Society of Cardiology (Dickstein et al. 2008; Jaarsma et al. 2009)

- "A palliative care approach is applicable to patients with HF and is particularly relevant to those with advanced disease."

- $\quad$ "Palliative care should be integrated as part of a team approach to comprehensive HF care and should not be reserved for those who are expected to die within days or weeks."

- “... clinicians should prepare for a 'change in gear' from a chronic stable disease management approach, to enhancement of the supportive and palliative care elements at times of crisis, and then to terminal care when death is imminent"

Table 3. Summary of recommendations of the various guideline agencies.

Conversely, it has only been over the last decade that the palliative needs of the HF population have started to be addressed. As recently as the late 1990's, the number of cancer patients in the United Kingdom (UK) receiving specialist palliative care services was more the 50-fold higher than the number of patients with heart disease receiving this care, despite an actual preponderance of deaths due to cardiovascular disease (Gibbs et al. 2002). Many potential barriers to the involvement of palliative care in this patient population have been identified, including the perceived unwillingness of cardiovascular specialists to seek palliative assistance, as this may be viewed as "giving up". While many treatments for cancer are associated with upfront side effects and difficulty, treatments for HF typically improve symptoms with relatively few side effects. There is also the perceived inability of palliative care specialists to manage complex cardiac patients (Gibbs et al. 2002). However as stated earlier, the main barrier is the inherent difficulty in estimating prognosis in this patient population, given the highly variable disease course. Despite these potential barriers, many cardiovascular associations now include palliative care provisions in their guideline 
documents (Table 3). The European guidelines also provide a general stepwise framework to facilitate the introduction of palliative care (Table 4). The most recent Canadian guidelines (McKelvie et al. 2011) contain practical tips in terms of carrying out many of these steps.

\section{Patient features}

- 1 of more episodes of decompensation per 6 months despite optimal tolerated therapy

- Need for frequent or continual IV support

- Chronic poor quality of life with NYHA IV symptoms

- Signs of cardiac cachexia

- Clinically judged to be close to the end of life

Confirm diagnosis

- $\quad$ Essential to ensure optimal treatment

Patient education

- $\quad$ Principles of self-care maintenance and management of HF

Establish an Advanced Care Plan

- Designed with the patient and a family member.

- Reviewed regularly and includes the patients' preferences for future treatment options (must involve provider(s) with knowledge and experience in care of $\mathrm{HF}$ )

Services should be organised

- The patients' care within the multidisciplinary team, to ensure optimal pharmacological treatment, self-care management and to facilitate access to supportive services.

Symptom Management

- Requires regular and frequent assessment of patients' physical, psychological, social and spiritual needs.

- $\quad$ Patients frequently have multiple co-morbidities that need to be identified.

Identifying end-stage heart failure

- Confirmation of end-stage HF is advisable to ensure that all appropriate treatment options have been explored a plan for the terminal stage of illness should be agreed upon.

Breaking bad news to the patient and family

- Explaining disease progression and a change in treatment emphasis is a sensitive issue and must be approached with care.

Establishing new goals of care

- End-of-life care should include avoidance of circumstances that may detract from a peaceful death.

- All current pharmacological treatment and device programmes should be considered.

- Resuscitation orders should be clear.

Table 4. Goals and steps in the process of providing palliative care in patients with heart failure (modified from the 2008 European Heart Failure Guidelines).

\subsection{The Importance of effective communication}

A critical component in the management of heart failure is communication. Given the progressive nature of HF, discussions should be carried out with patients and their family members in regards to advanced care-planning issues (Table 5). Ideally, these discussions 
should take place early in the course of the disease process, as patients with HF are not only at risk of dying from progressive heart failure, but sudden cardiac death as well. While the mortality rate increases as a function of NYHA class, the majority of deaths for patients with lesser NYHA class symptoms are due to sudden cardiac death (Hjalmarson and Goldstein 1999). Early discussion with subsequent updates as clinical condition changes also helps minimize any possible misunderstanding of prognosis. In one study of bereaved family members of heart failure patients with non-sudden cardiac deaths, only $8 \%$ of patients and $44 \%$ of family members were informed by a physician that time was limited (McCarthy and Hall 1997). It is worthwhile noting that in patients with end-stage refractory heart failure, discussing end-of-life plans and the option of turning off an ICD is a class I recommendation according to the ACC/AHA heart failure guidelines (Jessup et al. 2009). The 2011 Canadian heart failure update provides practical assistance in terms of how to conduct advanced careplanning discussions (McKelvie et al. 2011).

- Identification of a surrogate decision-maker.

- Introduction to "goals of care" designations, and establishing preferences for cardiopulmonary resuscitation and advanced life support.

- $\quad$ Encourage Living Wills and Advanced Directives.

- Exploration of non-traditional symptoms of heart failure in the physical, social, functional or psychological domains.

- The potential role and impact of other comorbidities and frailty in shaping or altering the patient's prognosis.

- Circumstances for discontinuing or turning off an invasive therapy, such as an ICD or other cardiac devices, hemodialysis, laboratory testing.

- Reassurance that periodic re-evaluation of preferences and treatment goals will occur.

- Potential treatment plan for sudden increase in symptoms while at home.

Table 5. Topics of discussion for advanced care planning (modified from (Howlett 2011)).

\subsection{Symptom management}

Patients with chronic HF experience a multitude of symptoms that have significant impact on their overall sense of wellbeing. The majority of these symptoms are the same as those experienced by cancer patients (Table 6). Unfortunately, non-cardiac symptoms are not commonly addressed in the context of a cardiovascular care setting (Boyd et al. 2004; Solano, Gomes, and Higginson 2006). Patients with HF are more likely to be admitted to hospital, more likely to be admitted to an intensive care unit once hospitalized, more likely to undergo invasive treatments, and more likely to die in an acute care setting (Setoguchi and Stevenson 2009). By ignoring non-cardiac symptoms, patients with HF are sub-optimally treated, leading to the potential of inappropriately aggressive care (Howlett 2011).

\begin{tabular}{|c|c|c|}
\hline Similar to Cancer & & Different from Cancer \\
\hline $\begin{array}{ll} & \text { Pain } \\
\text { - } & \text { Dyspnea } \\
\text { - } & \text { Anorexia } \\
\text { - } & \text { Postural } \\
& \text { Hypotension }\end{array}$ & $\begin{array}{ll}- & \text { Anxiety } \\
\text { - } & \text { Depression } \\
\text { - } & \text { Fatigue }\end{array}$ & $\begin{array}{l}\text { - } \quad \text { More edema } \\
\text { - } \quad \text { More renal dysfunction } \\
\text { - }\end{array}$ \\
\hline
\end{tabular}

Table 6. Common symptoms experienced by heart failure and cancer patients. 


\subsubsection{Dyspnea, fatigue, and exercise Impairment}

Dyspnea is the classic symptom of heart failure. Population studies have shown the incidence to range between 60 to 88\% (Solano, Gomes, and Higginson 2006). Severe dyspnea is observed in $35 \%$ of patients in the last 3 to 6 months of life (Krumholz et al. 1998). Both fatigue and exercise impairment are also commonly observed in association with dyspnea, with similar prevalence rates (Solano, Gomes, and Higginson 2006). All of these symptoms impact the ability of patients with HF to perform basic activities required for normal daily life, and thus have important implications in terms of their independence and quality of life. These symptoms also contribute to social isolation.

Nitrates and diuretics are the mainstay of treatment for dyspnea. Opioids have also been previously shown to be efficacious (Johnson et al. 2002). However, a recent placebocontrolled study of two different oral opioids (morphine and oxycodone) in patients with CHF was not able to demonstrate any benefit (Oxberry et al. 2011). Similarly, a Cochrane review failed to demonstrate the benefit of benzodiazepines for the relief of dyspnea (Simon et al. 2010), however it is worthwhile point out that this result is based on a total of only 64 patients from 4 different studies. Conversely, regular exercise training has been shown to have beneficial effects in terms of improvement in functional capacity, symptoms, and quality of life (Downing and Balady 2011; Crimi, Ignarro, and Cacciatore 2009). In addition, there also appears to be a modest reduction in repeat hospitalization and mortality (O'Connor et al. 2009). Lastly, alternative care models such as day hospice programs have been shown to be beneficial (Daley, Matthews, and Williams 2009).

\subsubsection{Pain}

Pain is the second most common symptom experienced by patients with end-stage HF, surpassed only by dyspnea (Nordgren and Sörensen 2003). Anti-anginals are the mainstay for anginal pain. Nonsteroidal anti-inflammatory drugs should be avoided, as they are associated with sodium retention and peripheral vasoconstriction, and can also attenuate the efficacy of diuretics and ACE inhibitors. Although both physicians and patients tend to be wary of opioids, addiction is rare in the terminal patient population (Kanner 2001). For moderate to severe pain, opioids should be used as first-line agents (Adler et al. 2009).

\subsubsection{Depression and anxiety}

Depression and anxiety are also common symptoms, with prevalences on the order of 20 to $48 \%$ and 18 to $45 \%$, respectively (Haworth and Moniz-Cook 2005). The prevalence of both of these symptoms is correlated with HF severity, with lower rates being observed in stable outpatient populations, and higher rates noted in patients with NYHA class IV symptoms. It is interesting to note that some HF therapies such as ICDs can increase anxiety and depression in certain patient subsets, particularly younger patients (Freedenberg, Thomas, and Friedmann 2011).

Patients with depression tend to do poorer than their non-depressed cohorts, in that they have increased rates of cardiac events and hospitalization (Rutledge et al. 2006). Death rates are also noted to be higher in depressed patients with HF (Rutledge et al. 2006). Many 
studies also show that higher anxiety and depression levels are related to an increased likelihood of ICD shocks (Freedenberg, Thomas, and Friedmann 2011).

Unfortunately, as with other symptoms in HF, large well-designed clinical trails have not been carried out to address optimal management in this patient population (Adler et al. 2009). An important component of managing depression and anxiety is the management of other symptoms, such as dyspnea and pain. While anti-depressants are commonly employed in the general patient population with depression, a recent observational study showed that the use of selective serotonin reuptake inhibitors (SSRIs) or tricyclic antidepressants (TCAs) in the HF patient population was associated with an increased risk of death (Fosbøl et al. 2009). In terms of SSRIs, this study showed that risk was further potentiated when they were co-administered with beta-blockers. Conversely, other studies such as the SAD Heart trial showed improved symptoms with no increase in mortality, although there was a trend for increased CV events in women (O'Connor, Jiang, and Kuchibhalta 2010). More research is required to help clarify this issue. From a nonpharmacologic perspective, cognitive behavioural therapy appears to be beneficial for reducing psychological distress in both the general HF population as well as patients with ICDs (Lewin et al. 2009; Dekker 2011).

\subsubsection{Sleep-disordered breathing}

Sleep-disordered breathing is common in patients with HF, with prevalence rates ranging up to 50 to $80 \%$ (Herrscher et al. 2011). Both central and obstructive etiologies have been observed in this patient population. Central sleep apnea (CSA) results from withdrawal of central drive to the respiratory muscles, whereas obstructive sleep apnea (OSA) results from complete or partial collapse of the pharynx. CSA appears to be a sign of more severe HF (Oldenburg et al. 2007). Both forms of sleep-disordered breathing have been associated with HF symptom progression, as well a poorer overall prognosis compared to patients with HF without sleep-disordered breathing (Javaheri, Shukla, and Zeigler 2007; Wang et al. 2007). Patients suspected of having sleep disordered breathing should be referred on to specialized sleep physicians for formal diagnosis and review of treatment options.

\subsubsection{Cardiac cachexia}

While cachexia is commonly associated with cancer, it is also observed in the advanced stages of other chronic illnesses including HF. Cardiac cachexia is a complex syndrome and is associated with poor clinical outcomes (Haehling et al. 2009). While anorexia contributes to cardiac cachexia, there are also profound metabolic and inflammatory changes that are observed in this syndrome (Haehling et al. 2009). Unfortunately, treatments targeted at the inflammatory pathways have not been successful. As with the other non-cardiac symptoms, more research is required to help establish optimal therapy, as even optimal nutritional recommendations are unknown at the current time (Haehling et al. 2009).

\section{Discontinuation of therapy}

In general terms, the initiation of various therapies for patients with HF is relatively straightforward. In many instances, there are consensus documents or formal guidelines 
published by the various cardiovascular governing agencies (e.g. ACC, AHA, CCS, ESC) to help guide appropriate therapy. Conversely, discontinuation of therapy does not have the same wealth of supporting evidence. In many instances, clinicians are left to make decisions on a patient-by-patient basis, particularly with the discontinuation of medications.

\subsection{Medications}

As stated at the beginning of this chapter, current patients with HF are older, have more comorbidities, and take more medications than in the past (Wong et al. 2011). During the time period of 2003 to 2008, patients with HF were taking an average of 6.4 prescription cardiac medications, with $10 \%$ of these patients taking more than an average of 11 cardiac medications (Wong et al. 2011). There are suggested methods (Steinman and Hanlon 2010; Bain, Holmes, and Beers 2008) but no guideline documents specific to HF to assist in the process of discontinuing medications for patients who may no longer be benefiting from them as they approach end of life. There does not even appear to be a consensus for medications such as statins whose benefits are achieved mainly with long term use (Vollrath, Sinclair, and Hallenbeck 2005; Davis 2006; Vollrath and Sinclair 2006). In many instances, practical constraints such as hypotension and renal dysfunction come into play. Additionally, patients may reach a point at which pill burden is a source of suffering or they are no longer able to swallow oral medications.

\subsection{Devices}

Over the course of the last several decades, medical devices have gained an increasingly significant role in the management of many patients with poor left ventricular ejection fraction. Current device options include ICDs, CRT-ICDs, and VADs. In 2008, more than 127,000 ICDs were implanted in the United States (Hammill et al. 2009). As indications for these devices continue to expand, a commensurate increase in the number of patients with these devices will likely be seen (Hammill et al. 2009). In addition, with an aging population, there will be an increasing number of patients with cardiac disease requiring advanced care including device therapy (Groarke et al. 2010).

While the implantation of these devices is directed by well-defined consensus guidelines that have been published by the various cardiovascular governing agencies (e.g. ACC, AHA, CCS, ESC), it has only been in the last year that formal deactivation policies have been published, with the support of other specialty agencies including palliative care (Lampert et al. 2010; Padeletti et al. 2010).

\subsubsection{ICDs and CRT devices}

As HF worsens, patients are likely to receive more frequent shocks, which cause significant pain and anxiety. This leads to not only patient distress, but also distress of their families and supporting health care team (Goldstein et al. 2004). Discontinuation of ICD therapy is an option for eliminating this distress. Ideally, conversations about when ICD therapy discontinuation would be warranted should be initiated at the time of implantation (Lampert et al. 2010). Not surprisingly, these early conversations occur infrequently (Goldstein, Mehta, and Siddiqui 2008). 
Patients must be informed that most ICDs and CRT devices have multiple functions, including tachy-arrhythmia therapies (shock, anti-tachycardia pacing), brady-arrhythmia therapies (conventional pacing), and cardiac resynchronization therapies (bi-ventricular pacing). In this regard, a decision must be made in terms of which functions will be discontinued. The input of a cardiovascular specialist is essential in this regard, as the benefits and burdens of each individual therapy can be reviewed. The majority of patients and their care providers typically elect to only suspend the tachy-arrhythmia therapies (shock, anti-tachycardia pacing), keeping the brady-arrhythmia and cardiac resynchronization therapies (if applicable) in place.

The recent consensus statement published by the Heart Rhythm Society (HRS) states that device deactivation requires a written order from the responsible physician (in emergent situations, a verbal order can be used, followed by written documentation within 24 hours). The ordering physician does not necessarily have to be a cardiologist or cardiac electrophysiologist, but can be the patient's primary care physician, or a hospitalist or palliative care specialist. The written order must address a number of points, as summarized in Table 7.

- Confirmation that the patient (or legal surrogate) has requested device deactivation.

- Capacity of the patient to make the decision, or identification of the appropriate surrogate.

- Confirmation that alternative therapies have been discussed if relevant.

- Confirmation that consequences of deactivation have been discussed.

- The specific device therapies to be deactivated.

- Notification of family, if appropriate.

Table 7. Points for discussion and documentation for device discontinuation (modified from Lampert et al, 2010).

\subsubsection{VADs}

Left ventricular assist devices have only recently been approved for use as "destination therapy"(Boilson et al. 2010), a term which refers to long term mechanical circulatory support in patients with end-stage heart failure (Boilson et al. 2010). Unlike ICDs and CRT devices, the implantation of a VAD requires open-heart surgery, and as such is associated with all of the associated peri-operative risks. At the present time, the surgical mortality rate is on the order of 5 to $10 \%$ (Lund, Jennifer Matthews, and Aaronson 2010). Many patients with significant comorbid conditions will not be suitable for this kind of support. Post implantation, patients are left with a number of on-going medical risks including infection, bleeding, and stroke. Even with a VAD in place, two-year mortality is on the order of $40-50 \%$.

VADs impose a psychosocial strain on both patients and their caregivers (Swetz et al. 2011). In recognition of the unique medical and the psychosocial needs of VAD patients, Petrucci and colleagues have developed a framework that addresses the ethical and psychosocial issues that should be discussed with these patients (Petrucci et al. 2011). This framework is provided in Table 8. 


\section{Phase I: Initial Information (Understanding Consent)}

- Surgical intervention: physical events leading up to this type of surgical intervention including elective vs. emergency consideration.

- Device technology: current device technology including risks, benefits, and outcomes with possible future surgical revisions. VAD as a therapy and rescue device rather than a "cure," with mortality and morbidity remaining high as per recent trials. Review realistic vs. idealistic expectations for recovery.

- Expected recovery: reasons and length of time for expected hospital course and usual recovery after heart surgery.

- Changing plans: the notions that "care plans" can change at any time based on physical, hemodynamic, or neurologic needs. Discuss unexpected events such as machine withdrawal, technical failure, and pump replacement.

\section{Phase II: Pre-implant Preparation (Future Directions)}

- Care planning: necessity of advance directives and care planning specific to BTT/DT before implant.

- Appointing a decision maker: appoint a spokesperson, with possible need for capacity determination, neurologic or psychiatric evaluations, and involvement of the institution's risk management group.

- Cultural preference: consider possible cultural and religious preferences.

- Conflict resolution: involve institution's ethics committee when conflicts persist beyond advance care planning between family expectations and patient's progress.

Phase III: VAD-Specific End-of-Life Issues (Withdrawing Care)

- Palliative plan: defining and discussion of ECMO, DNR, and DNI orders, and removal of life support in light of mechanical support. Discuss palliative or comfort care in hospital, home, or other facility.

- Acceptable withdrawal: develop an acceptable device withdrawal process for patient and family.

Abbreviations:

- $\mathrm{BTT}$, bridge to transplant; DNI, do not intubate; DNR, do not resuscitate; DT, destination therapy; ECMO, extracorporeal membrane oxygenation;

Table 8. A framework for ethical and psychosocial issues associated VADS (modified from Petrucci et al., 2011).

\section{Conclusion}

Heart failure is a progressive disease responsible for significant morbidity and mortality throughout the world. There is no question that advances in medical therapy have improved the prognosis of this patient population. But with these advances, other elements in the care of these patients have been neglected. Specifically, patients with HF commonly have a poor overall sense of well-being. Optimal therapy in this regard remains unknown but it is unlikely that medical and technology advances alone will improve well-being (O'Leary and Murphy 2009). In addition, unique issues arise, including the indications and timing for discontinuation of these therapies at end-of-life. Evolution of HF care in the future will incorporate elements of palliative care (sensitive communication, attention to patient's goals, family and caregiver support assessment and attending to all a persons' needs) with the medical model of "cardiac optimization", throughout all phases of the 
disease trajectory. Working across disciplines to translate guidelines from various cardiovascular governing bodies into practice may help to facilitate this approach.

\section{References}

Abouezzeddine, Omar F, and Margaret M Redfield. 2011. “Who has advanced heart failure? Definition and epidemiology." Congestive heart failure (Greenwich, Conn.) 17 (4) 160 168.

Adler, E D, J Z Goldfinger, J Kalman, M E Park, and D E Meier. 2009. “Palliative Care in the Treatment of Advanced Heart Failure." Circulation 120 (25) 2597-2606.

Bain, KT, HM Holmes, and MH Beers. 2008. "Discontinuing Medications: A Novel Approach for Revising the Prescribing Stage of the Medication-Use Process." Jurnal of the American Geriatrics Society 56(10): 1946-52.

Boilson, Barry A, Eugenia Raichlin, Soon J Park, and Sudhir S Kushwaha. 2010. "Device therapy and cardiac transplantation for end-stage heart failure." Current problems in cardiology 35 (1) 8-64.

Boyd, Kirsty J, Scott A Murray, Marilyn Kendall, Allison Worth, T Frederick Benton, and Hans Clausen. 2004. "Living with advanced heart failure: a prospective, community based study of patients and their carers.." European journal of heart failure 6 (5) 585-591.

Braunschweig, Frieder, Martin R Cowie, and Angelo Auricchio. 2011. "What are the costs of heart failure?." Europace 13 Suppl 2 ii13-7.

Crimi, E, LJ Ignarro, and F Cacciatore. 2009. "Mechanisms by which exercise training benefits patients with heart failure." Nature Reviews Cardiology. 6(4): 292-300.

Daley, Andrew, Christine Matthews, and Anne Williams. 2006. "Heart failure and palliative care services working in partnership: report of a new model of care.." Palliative medicine 20 (6) 593-601.

Davis, George F. 2006. "Discontinuing Lipid-Lowering Agents." Journal of palliative medicine 9 (3) 619-619.

Dekker, Rebecca L. 2011. “Cognitive Therapy for Depression in Patients with Heart Failure: A Critical Review." Heart failure clinics 7 (1) 127-141.

Dickstein, K, A Cohen-Solal, G Filippatos, J J V McMurray, P Ponikowski, P A Poole-Wilson, A Stromberg, et al. 2008. "ESC Guidelines for the diagnosis and treatment of acute and chronic heart failure 2008: The Task Force for the Diagnosis and Treatment of Acute and Chronic Heart Failure 2008 of the European Society of Cardiology. Developed in collaboration with the Heart Failure Association of the ESC (HFA) and endorsed by the European Society of Intensive Care Medicine (ESICM)." European Heart Journal 29 (19) 2388-2442.

Downing, Jill, and Gary J Balady. 2011. "The role of exercise training in heart failure.." Journal of the American College of Cardiology 58 (6) 561-569.

Foot, D K, R P Lewis, T A Pearson, and G A Beller. 2000. “Demographics and cardiology, 1950-2050.." Journal of the American College of Cardiology 35 (5 Suppl B) (April): 66B$80 \mathrm{~B}$.

Fosbøl, Emil Loldrup, Gunnar H Gislason, Henrik Enghusen Poulsen, Morten Lock Hansen, Fredrik Folke, Tina Ken Schramm, Jonas Bjerring Olesen, et al. 2009. “Prognosis in heart failure and the value of $\{$ beta\}-blockers are altered by the use of 
antidepressants and depend on the type of antidepressants used.." Circulation: Heart Failure 2 (6) 582-590.

Freedenberg, Vicki, Sue A Thomas, and Erika Friedmann. 2011. “Anxiety and depression in implanted cardioverter-defibrillator recipients and heart failure: a review.." Heart failure clinics 7 (1) 59-68.

Gibbs, J S R, A S M McCoy, L M E Gibbs, A E Rogers, and J M Addington-Hall. 2002. "Living with and dying from heart failure: the role of palliative care." Heart (British Cardiac Society) 88 Suppl 2 ii36-9.

Goldstein, Nathan E, Rachel Lampert, Elizabeth Bradley, Joanne Lynn, and Harlan M Krumholz. 2004. "Management of implantable cardioverter defibrillators in end-oflife care.." Annals of internal medicine 141 (11) 835-838.

Goldstein, NE, D Mehta, and S Siddiqui. 2008. "“That"s Like an Act of Suicide" Patients" Attitudes Toward Deactivation of Implantable Defibrillators." Journal of general internal medicine. 23 Suppl 1: 7-12.

Goodlin, Sarah J. 2009. "Palliative care in congestive heart failure.." Journal of the American College of Cardiology 54 (5) 386-396.

Groarke, J D, G Blake, H McCann, D Sugrue, and N Mahon. 2010. “Increasing cardiac interventions among the aged.." Irish medical journal 103 (10) (October): 308-310.

Haehling, von, Stephan, Mitja Lainscak, Jochen Springer, and Stefan D Anker. 2009. "Cardiac cachexia: A systematic overview." Pharmacology \& Therapeutics 121 (3) 227-252.

Hammill, Stephen C, Mark S Kremers, Alan H Kadish, Lynne Warner Stevenson, Paul A Heidenreich, Bruce D Lindsay, Michael J Mirro, et al. 2009. "Review of the ICD Registry's third year, expansion to include lead data and pediatric ICD procedures, and role for measuring performance.." Heart rhythm : the official journal of the Heart Rhythm Society 6 (9) 1397-1401.

Haworth, JE, and E Moniz-Cook. 2005. "Prevalence and predictors of anxiety and depression in a sample of chronic heart failure patients with left ventricular systolic dysfunction." European journal of heart failure 7(5):803-8.

Herrscher, Tobias E, Harriet Akre, Britt Øverland, Leiv Sandvik, and Arne S Westheim. 2011. "High Prevalence of Sleep Apnea in Heart Failure Outpatients: Even in Patients With Preserved Systolic Function." Journal of cardiac failure 17 (5) 420-425.

Hinton, JM. 1963. "The physical and mental distress of the dying.." The Quarterly journal of medicine 32:1-21.

Hjalmarson, $\AA$, and USA) B Fagerberg secretary Sweden H Wedel biostatistician Sweden F Waagstein Sweden J Kjekshus Norway J Wikstrand senior medical advisor Astra Hässle Sweden G Westergren project leader Astra Hässle Sweden S Goldstein cochairman. 1999. "Effect of metoprolol CR/XL in chronic heart failure: Metoprolol CR/XL Randomised Intervention Trial in Congestive Heart Failure (MERIT-HF)." The Lancet 353 (9169) 2001-2007.

Howlett, Jonathan G. 2011. "Palliative care in heart failure: addressing the largest care gap.." Current opinion in cardiology 26 (2) 144-148.

Jaarsma, T, J M Beattie, M Ryder, F H Rutten, T McDonagh, P Mohacsi, S A Murray, et al. 2009. "Palliative care in heart failure: a position statement from the palliative care workshop of the Heart Failure Association of the European Society of Cardiology." European journal of heart failure 11 (5) 433-443. 
Javaheri, S, R Shukla, and H Zeigler. 2007. “ScienceDirect - Journal of the American College of Cardiology: Central Sleep Apnea, Right Ventricular Dysfunction, and Low Diastolic Blood Pressure Are Predictors of Mortality in Systolic Heart Failure." Journal of the American College of Cardiology 49(20): 2028-34.

Jessup, M, W T Abraham, D E Casey, A M Feldman, G S Francis, T G Ganiats, M A Konstam, et al. 2009. "2009 Focused Update: ACCF/AHA Guidelines for the Diagnosis and Management of Heart Failure in Adults: A Report of the American College of Cardiology Foundation/American Heart Association Task Force on Practice Guidelines: Developed in Collaboration With the International Society for Heart and Lung Transplantation." Circulation 119 (14) 1977-2016.

Johnson, M J, T A McDonagh, A Harkness, S E McKay, and H J Dargie. 2002. "Morphine for the relief of breathlessness in patients with chronic heart failure--a pilot study.." European journal of heart failure 4 (6) 753-756.

Kanner, R M. 2001. "Opioids for severe pain: little change over 15 years.." Journal of pain and symptom management 21 (1) 3.

Kaul, P, F A McAlister, J A Ezekowitz, J A Bakal, L H Curtis, H Quan, M L Knudtson, and P W Armstrong. 2011. "Resource Use in the Last 6 Months of Life Among Patients With Heart Failure in Canada." Archives of internal medicine 171 (3) 211-217.

Krumholz, HM, RS Phillips, MB Hamel, and JM Teno. 1998. "Resuscitation preferences among patients with severe congestive heart failure: results from the SUPPORT project." Circulation 98(7): 648-55.

Lampert, Rachel, David L Hayes, George J Annas, Margaret A Farley, Nathan E Goldstein, Robert M Hamilton, G Neal Kay, et al. 2010. HRS Expert Consensus Statement on the Management of Cardiovascular Implantable Electronic Devices (CIEDs) in patients nearing end of life or requesting withdrawal of therapy. In Heart rhythm : the official journal of the Heart Rhythm Society, 7:1008-1026. July.

Lewin, R J, S Coulton, D J Frizelle, G Kaye, and H Cox. 2009. “A brief cognitive behavioural preimplantation and rehabilitation programme for patients receiving an implantable cardioverter-defibrillator improves physical health and reduces psychological morbidity and unplanned readmissions.." Heart (British Cardiac Society) 95 (1) 63-69.

Lloyd-Jones, Donald, Robert J Adams, Todd M Brown, Mercedes Carnethon, Shifan Dai, Giovanni de Simone, T Bruce Ferguson, et al. 2010. “Executive summary: heart disease and stroke statistics--2010 update: a report from the American Heart Association." Circulation 121 (7) 948-954.

Lund, Lars H, Jennifer Matthews, and Keith Aaronson. 2010. "Patient selection for left ventricular assist devices.." European journal of heart failure 12 (5) 434-443.

McCarthy, M, and JA Hall. 1997. "Communication and choice in dying from heart disease.." Journal of the Royal Society of Medicine 90(3):128-31.

McKelvie, Robert S, Gordon W Moe, Anson Cheung, Jeannine Costigan, Anique Ducharme, Estrellita Estrella-Holder, Justin A Ezekowitz, et al. 2011. “The 2011 Canadian Cardiovascular Society heart failure management guidelines update: focus on sleep apnea, renal dysfunction, mechanical circulatory support, and palliative care.." The Canadian journal of cardiology 27 (3) 319-338.

Murray, Sa, A Worth, K Boyd, M Kendall, and J Hockley. 2007. Patients', carers' and professionals' experiences of diagnosis, treatment and end-of-life care in heart failure: a prospective, qualitative interview study. British Heart Foundation. 
Murray, Scott A, K Boyd, M Kendall, A Worth, and TF Benton. 2002. “Dying of lung cancer or cardiac failure: prospective qualitative interview study of patients and their carers in the community." British Medical Jurnal 325:924.

Murray, Scott A, and Aziz Sheikh. 2008. "Palliative Care Beyond Cancer: Care for all at the end of life.." BMJ (Clinical research ed.) 336 (7650) 958-959.

Murthy, Sandhya, and Hannah I Lipman. 2011. "Management of end-stage heart failure.." Primary care 38 (2) 265-76, viii.

Nordgren, Lena, and Stefan Sörensen. 2003. "Symptoms experienced in the last six months of life in patients with end-stage heart failure.." European journal of cardiovascular nursing : journal of the Working Group on Cardiovascular Nursing of the European Society of Cardiology 2 (3) 213-217.

O'Connor, Christopher M, David J Whellan, Kerry L Lee, Steven J Keteyian, Lawton S Cooper, Stephen J Ellis, Eric S Leifer, et al. 2009. “Efficacy and safety of exercise training in patients with chronic heart failure: HF-ACTION randomized controlled trial.." JAMA : the journal of the American Medical Association 301 (14) 1439-1450.

O'Connor, CM, W Jiang, and M Kuchibhatla. 2010. "Safety and Efficacy of Sertraline for Depression in Patients With Heart Failure:: Results of the SADHART-CHF (Sertraline Against Depression and Heart Disease in Chronik Heart Failure "Journal of the American College of Cardiology 56(9):692-9.

O'Leary, N, and NF Murphy. 2009. "A comparative study of the palliative care needs of heart failure and cancer patients." European Journal of heart failure 11(4):406-12.

Oldenburg, O, B Lamp, L Faber, H TESCHLER, D HORSTKOTTE, and V TOPFER. 2007. "Sleep-disordered breathing in patients with symptomatic heart failureA contemporary study of prevalence in and characteristics of 700 patients." European journal of heart failure 9 (3) 251-257.

Oxberry, Stephen G, David J Torgerson, J Martin Bland, Andrew L Clark, John G F Cleland, and Miriam J Johnson. 2011. "Short-term opioids for breathlessness in stable chronic heart failure: a randomized controlled trial.." European journal of heart failure 13(9):1006-12.

Padeletti, L, D O Arnar, L Boncinelli, J Brachman, J A Camm, J C Daubert, S Kassam, et al. 2010. "EHRA Expert Consensus Statement on the management of cardiovascular implantable electronic devices in patients nearing end of life or requesting withdrawal of therapy." Europace 12 (10) 1480-1489.

Petrucci, Ralph J, Lynne A Benish, Barbara L Carrow, Lisa Prato, Shelley R Hankins, Howard J Eisen, and John W Entwistle. 2011. "Ethical considerations for ventricular assist device support: a 10-point model.." ASAIO journal (American Society for Artificial Internal Organs: 1992) 57 (4) 268-273.

Rutledge, Thomas, Veronica A Reis, Sarah E Linke, Barry H Greenberg, and Paul J Mills. 2006. "Depression in Heart Failure." Journal of the American College of Cardiology 48 (8) 1527-1537.

Selman, L, R Harding, and T Beynon. 2007. “Modelling services to meet the palliative care needs of chronic heart failure patients and their families: current practice in the UK." Palliative Medicine 21(5):385-90.

Setoguchi, Soko, and Lynne Warner Stevenson. 2009. "Hospitalizations in patients with heart failure: who and why.." Journal of the American College of Cardiology 54 (18) 1703-1705. 
Simon, Steffen T, Irene J Higginson, Sara Booth, Richard Harding, and Claudia Bausewein. 2011. "Benzodiazepines for the relief of breathlessness in advanced malignant and non-malignant diseases in adults.." Cochrane database of systematic reviews.

Solano, Joao Paulo, Barbara Gomes, and Irene J Higginson. 2006. "A comparison of symptom prevalence in far advanced cancer, AIDS, heart disease, chronic obstructive pulmonary disease and renal disease.." Journal of pain and symptom management 31 (1) 58-69.

Steinman, M A, and J T Hanlon. 2010. "Managing Medications in Clinically Complex Elders: 'There's Got to Be a Happy Medium'." JAMA : the journal of the American Medical Association 304 (14) 1592-1601.

Swetz, Keith M, Abigale L Ottenberg, Monica R Freeman, and Paul S Mueller. 2011. "Palliative Care and End-of-Life Issues in Patients Treated with Left Ventricular Assist Devices as Destination Therapy." Current heart failure reports (May 3).

Temel, Jennifer S, Joseph A Greer, Alona Muzikansky, Emily R Gallagher, Sonal Admane, Vicki A Jackson, Constance M Dahlin, et al. 2010. "Early palliative care for patients with metastatic non-small-cell lung cancer." The New England journal of medicine 363 (8) 733-742.

Vollrath, AM, and C Sinclair. 2006. "Lipid-Lowering Agents: The Authors' Response." Journal of Palliative Medicine 8(4):876-81

Vollrath, Annette M, Christian Sinclair, and James Hallenbeck. 2005. "Discontinuing Cardiovascular Medications at the End of Life: Lipid-Lowering Agents." Journal of palliative medicine 8 (4) 876-881.

Wang, H, JD Parker, GE Newton, and JS Floras. 2007. “Influence of obstructive sleep apnea on mortality in patients with heart failure." Journal of the American College of Cardiology 49(15):1625-31.

Wong, C Y, S I Chaudhry, M M Desai, and H M Krumholz. 2011. “Trends in Comorbidity, Disability, and Polypharmacy in Heart Failure." AJM 124 (2) 136-143. 


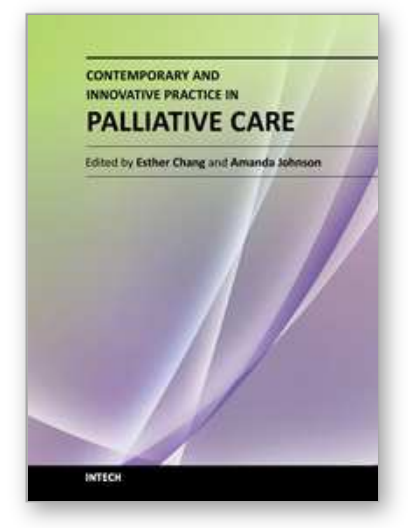

\author{
Contemporary and Innovative Practice in Palliative Care \\ Edited by Prof. Esther Chang
}

ISBN 978-953-307-986-8

Hard cover, 302 pages

Publisher InTech

Published online 10, February, 2012

Published in print edition February, 2012

This book is designed to provide a comprehensive insight unto the key and most prevalent contemporary issues associated with palliation. The reader will find viewpoints that are challenging and sometimes discerning, but at the same time motivating and thought-provoking in the care of persons requiring palliation. This book is divided into three sections. Section 1 examines contemporary practice; Section 2 looks at the challenges in practice; Section 3 discusses models of care. This book is an excellent resource for students, practising clinicians and academics. By reading the book, reflecting on the issues, challenges and opportunities ahead, we hope it will create within the reader a passion to take on, explore and further develop their palliative care practice.

\title{
How to reference
}

In order to correctly reference this scholarly work, feel free to copy and paste the following:

Michael Slawnych, Jessica Simon and Jonathan Howlett (2012). The Changing Landscape - Palliative Care in the Heart Failure Patient Population, Contemporary and Innovative Practice in Palliative Care, Prof. Esther Chang (Ed.), ISBN: 978-953-307-986-8, InTech, Available from:

http://www.intechopen.com/books/contemporary-and-innovative-practice-in-palliative-care/the-changinglandscape-palliative-care-in-the-heart-failure-patient-population

\section{INTECH}

open science | open minds

\author{
InTech Europe \\ University Campus STeP Ri \\ Slavka Krautzeka 83/A \\ 51000 Rijeka, Croatia \\ Phone: +385 (51) 770447 \\ Fax: +385 (51) 686166 \\ www.intechopen.com
}

\author{
InTech China \\ Unit 405, Office Block, Hotel Equatorial Shanghai \\ No.65, Yan An Road (West), Shanghai, 200040, China \\ 中国上海市延安西路65号上海国际贵都大饭店办公楼 405 单元 \\ Phone: +86-21-62489820 \\ Fax: +86-21-62489821
}


(C) 2012 The Author(s). Licensee IntechOpen. This is an open access article distributed under the terms of the Creative Commons Attribution 3.0 License, which permits unrestricted use, distribution, and reproduction in any medium, provided the original work is properly cited. 